\title{
Erratum to: Assessing the feasibility of the Effectiveness of Discontinuing Bisphosphonates trial: a pilot study
}

\author{
N. C. Wright ${ }^{1}$ • P. J. Foster ${ }^{2}$ • A. S. Mudano ${ }^{2}$ - J. A. Melnick ${ }^{2}$ • E. M. Lewiecki ${ }^{3}$ • \\ W. J. Shergy ${ }^{4}$ J. R. Curtis ${ }^{2}$ - G. R. Cutter ${ }^{5}$ - M. I. Danila ${ }^{2}$ - M. L. Kilgore ${ }^{6}$. \\ E. C. Lewis ${ }^{7}$ - S. L. Morgan ${ }^{2}$ - D. T. Redden ${ }^{5}$ - A. H. Warriner $^{8}$ - K. G. Saag ${ }^{2}$
}

Published online: 7 June 2017

(C) International Osteoporosis Foundation and National Osteoporosis Foundation 2017

\section{Erratum: Osteoporos Int}

DOI 10.1007/s00198-017-4073-5

The fifth author of this article was incorrectly listed as "M. E. Lewiecki"; however, the name should be "E. M. Lewiecki." The corresponding author sincerely regrets this error.

The online version of the original article can be found at http://dx.doi.org/ 10.1007/s00198-017-4073-5

N. C. Wright

ncwright@uab.edu

1 Department of Epidemiology, University of Alabama at Birmingham, Birmingham, AL, USA

2 Division of Clinical Immunology and Rheumatology, University of Alabama at Birmingham, Birmingham, AL, USA

3 New Mexico Clinical Research and Osteoporosis Center, Albuquerque, NM, USA

4 Rheumatology Associates of North Alabama, Huntsville, AL, USA

5 Department of Biostatistics, University of Alabama at Birmingham, Birmingham, AL, USA

6 Deparment of Health Care Organization and Policy, University of Alabama at Birmingham, Birmingham, AL, USA

7 Division of Preventive Medicine, University of Alabama at Birmingham, Birmingham, AL, USA

8 Division of Endocrinology, Diabetes and Metabolism, University of Alabama at Birmingham, Birmingham, AL, USA 